\title{
Interactive sandwich facade made of renewable resources
}

\author{
Sandra Gelbrich, Carolin Petzoldt*, Ralf Gliniorz, Andreas Ehrlich, and Lothar Kroll \\ Department of Lightweight Structures and Polymer Technology, 09126 Chemnitz, Germany
}

\begin{abstract}
This paper reports about the development and implementation of a free forming facade system, consisting of biobased sandwich elements. The build-up of the sandwich contains face sheets from natural fibre reinforced polymer (NFRP), using biobased epoxy resin and flax fibres, and a stuck cardboard core structure. Furthermore a formwork system was designed enabling biobased sandwich elements to be produced with special needs according to efficiency and architectural design. As a result, the biobased and sustainable sandwich elements exhibit low system weight, high sound reduction and sufficient load capacity for the use of facade elements. Additionally LED-stripes were integrated for illuminating the facade elements. Because of the regular pattern of the stuck cardboard core and the translucent face sheet laminates the facade works like a screen on which each created pixel can be controlled in rgb-colours. Therefore an area of $10 \mathrm{~m} \times 5 \mathrm{~m}$ biobased sandwich facade with 25 elements is planned as a reference object in Chemnitz, forming a facade with 100 x 48 pixels. In summary the illuminated biobased sandwich elements produced with an efficient technology of production and with the use of renewable resources can replace extensively 3D-formed customary facade systems.
\end{abstract}

\section{Introduction}

Globally, the growth of population and economy increase the consumption of natural resources and energy from non-renewable materials, like raw oil, natural gas, coal and uranium [1]. More than $30 \%$ of total energy consumption and more than $50 \%$ of raw material consumption are used for the construction industry with their emerged buildings [2]. This aspect causes growing interests in many countries and international politics for sustainability in the last 20 years. Hence the building envelope as an integral part of buildings and renewable resources have a key role for the implementation of sustainability. So the use of natural fibre reinforcement and biobased materials contribute the reduction of limited fossil resources and optimize the whole ecological balance sheet and concept of sustainability within the building industry.

In this context fibre reinforced polymer (FRP) composites, consisting of natural fibres and biobased resin systems, are predestined being used in facade elements for buildings. They are ecologically beneficial and energy efficient and are supposed to replace less environmental and petrochemical FRP [3]. Current application fields for natural fibre

\footnotetext{
* Corresponding author: carolin.petzoldt@mb-.tu-chemntiz.de
} 
reinforced polymers (NFRP) are for example automotive industry, bio-medicine, packaging industry and building industry [4-6]. Natural fibres, like domestic flax, hemp or jute have low fibre density and similar specific stiffness compared to glass fibres, what is interesting for the use as fibre reinforcement in lightweight structures and components in the building industry. Furthermore natural fibres have the distinction of a low energy demand of 9.55 $\mathrm{MJ} / \mathrm{kg}$ (flax fibres) in comparison to glass fibres mats with $54.7 \mathrm{MJ} / \mathrm{kg}$ [7]. Moreover the biobased resin component has a significantly reduced carbon footprint of about $40 \%$ compared to petrochemical resin systems (embodied energy of $76 \mathrm{MJ} / \mathrm{kg}$ ) [8].

Research in the fields of innovative facade structures from biobased materials with high potential for lightweight design has been object of intensive scientific and applicationoriented efforts for a couple of years

(e. g. [9-11]). Also the integration of additional functions like the illumination of elements are shown in the development of a smart GRFP honeycomb sandwich for interactive bridges [12].

Therefore the aim of the project was the development of a free forming facade system from biobased materials and integrated functions (like illuminating the elements) used in the field of modern architecture.

\section{Method of Solution}

\subsection{Materials and sample preparation}

Figure 1 illustrates the build-up of the biobased sandwich element with two face sheets covering a core component. They are adhered with each other and transmit forces and stresses, like a traditional sandwich element [13]. The face sheets are from NFRP, consisting of a flax fibre reinforcement and biobased resin matrix. Therefor two layers of a bidirectional flax fibre woven fabric (surface weight of $400 \mathrm{~g} / \mathrm{m}^{2}$ ) were integrated in an epoxy resin, based on biological components with $56 \%$ carbon from vegetable origin. The face sheet laminates show a tensile strength of $67 \mathrm{MPa}$, a bending strength of $97 \mathrm{MPa}$ and a Young's modulus of 5.6 MPa, based on a calculated fibre volume content of $24 \mathrm{Vol} .-\%$.

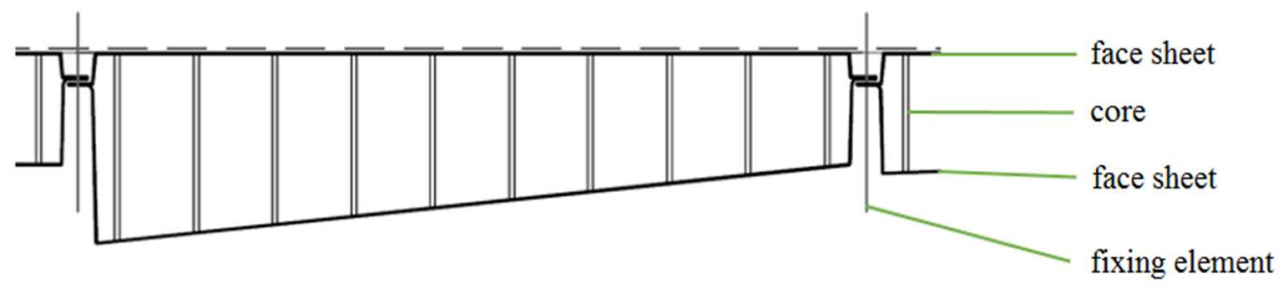

Fig. 1. Facade element, horizontal sectional drawing

The used core material was a stuck cardboard structure (Figure 2, b) with advantages according to low weight, resource efficiency, recyclability and the use of recycled material. The cardboard material consists of a BC-flute with a material thickness of $6.91 \mathrm{~mm}$ and a surface weight of $1191 \mathrm{~g} / \mathrm{m}^{2}$. So the cardboard was cut in 2D elements and stuck together to build a $3 \mathrm{D}$ core component. The width of the compartments as well as the height of the core component amounted $100 \mathrm{~mm}$ to $200 \mathrm{~mm}$. Additional a special coating based on sodium silicate was applied to protect the cardboard material against environmental conditions and to avoid water absorption and inflammability. Several specimen were prepared for the mechanical and physical characterization of the materials and material composites. The 
manufacturing process of the face sheet laminates occurred with hand lay-up process. Furthermore the cardboard core was processed "wet-in-wet".

a)

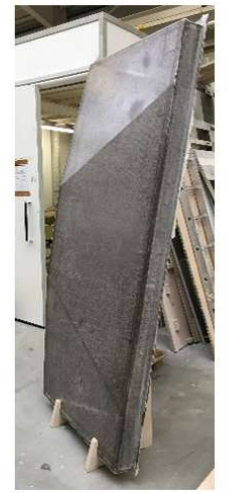

b)

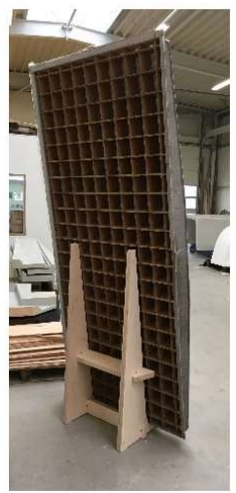

Fig. 2. Biobased facade element without second NFRP face sheet laminate (a: front view, b: rear view)

\subsection{Characterization}

The NFRP laminates were tested according to water vapour diffusion following DIN EN ISO 12572. The round samples with a diameter of $80 \mathrm{~mm}$ were adhered airtight on top of a glass receptacle with the drying agent calcium chloride $(\mathrm{CaCl} 2)$ inside (Figure 3 , a). With a defined temperature and humidity of $23^{\circ} \mathrm{C}$ and $50 \%$ the water vapour transmission between the surrounding air and the specimen were measured.

To validate the cardboard core the flammability and flame dispersion was determined by means of the flammability test apparatus CEAST UL 94, with samples which measures $90 \times 230 \mathrm{~mm}^{2}$ based on DIN EN 13501-1 class E (Figure 3, b). Furthermore the water absorption was measured by means of the Cobb-Unger test apparatus based on DIN EN ISO 535 (Figure 3, c). The Cobb60 value determines the calculated mass of water, which is absorbed in $60 \mathrm{~s}$ from $1 \mathrm{~m}^{2}$ cardboard.

a)

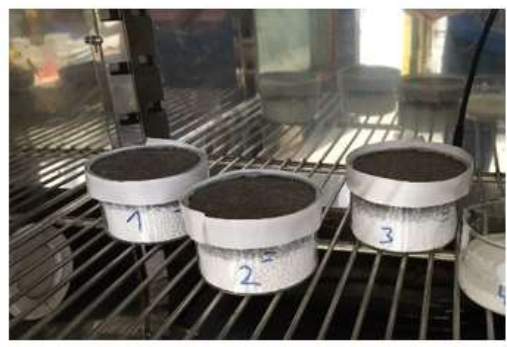

b)

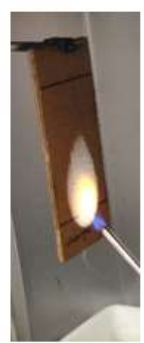

c)

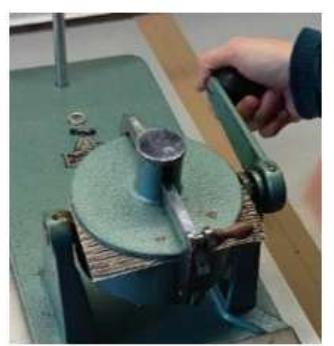

Fig. 3. NFRP-samples for water vapour diffusion (a), cardboard sample whilst fire test (b) and CobbUnger test apparatus (c)

The validation of the biobased sandwich element includes 4-point-bending tests by means of the Toni Technik ToniNorm with samples which measured $1000 \times 200 \times 100 \mathrm{~mm}^{3}$ (length $\times$ width $\times$ height). The span width set was $900 \mathrm{~mm}$, the upper support distance was $300 \mathrm{~mm}$ and the load speed $50 \mathrm{~N} / \mathrm{s}$ constant. Furthermore the flammability and flame dispersion were measured, as well as the sound reduction and thermal conductivity. So the sound reduction index were determined by means of the SINUS transmission tube AFD 1200 Acoustic Tube based on DIN EN ISO 717-1. The round samples had a diameter of $40 \mathrm{~mm}$ and a height of $100 \mathrm{~mm}$. In Addition to that the thermal conductivity was determined by means of an institutes own test bench based on DIN 12667, where two samples are measured 
simultaneously. Arranged heating and cooling elements induce temperature differences to measure the thermal conductivity. Furthermore the flammability and flame dispersion of biobased sandwich composite were determined by means of a single burning item test (Figure 4 , b) following DIN EN 13823 with samples which consisted of two sample parts arranged like a corner, which measured $500 \times 155 \times 1500 \mathrm{~mm}^{3}$ and $1000 \times 155 \times 1500 \mathrm{~mm}^{3}$ (Figure 4, a). The test specimen have been stored for conditioning until constant mass according to DIN EN 13238-6 prior to testing. Further determinations according to flammability and flame dispersion following DIN EN ISO $11925-2$ with samples which measured $90 \times 50 \times 250 \mathrm{~mm}^{3}$ and a classification regarding reaction to fire tests based on DIN EN 13501-1 were realized.

a)

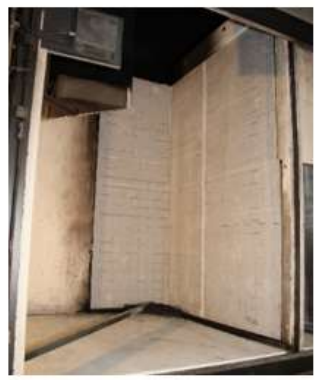

b)

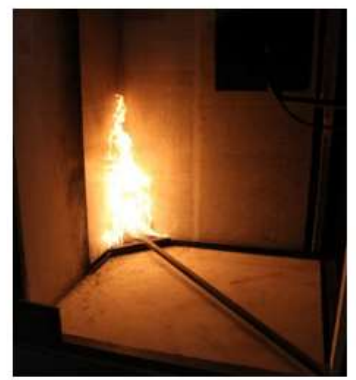

c)

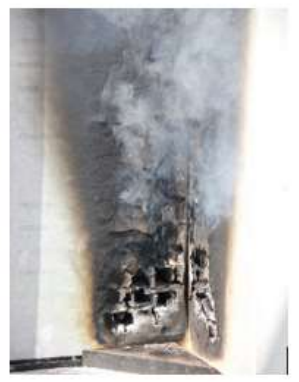

Fig. 4. Biobased sandwich element for single burning item test according to DIN EN 13823 (a) with defined flame (b), and smoke formation after single burning item test (c)

\subsection{Integration of function and reference object}

The benefit of the cardboard core consists of sustainability, light weight character and high stiffness. But the unique characteristic is created by the regular pattern of the stuck cardboard structure. They shape square-formed cavities between the translucent face sheets and can so be illuminated as pixels of a matrix screen. With the use of special LED-stripes each resulting pixel is separately activated by a controller and all pixel together form a matrix screen in rgbcolours, which can give out information or advertising (Figure 5, a).

Based on an architectural design the biobased sandwich elements will be mounted on a production building in Chemnitz, Germany. It replaces a part of a building front on an area of $10 \times 5 \mathrm{~m}^{2}$ (Figure $\left.5, \mathrm{~b}\right)$.

a)

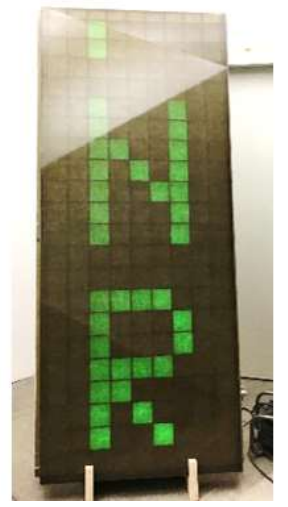

b)

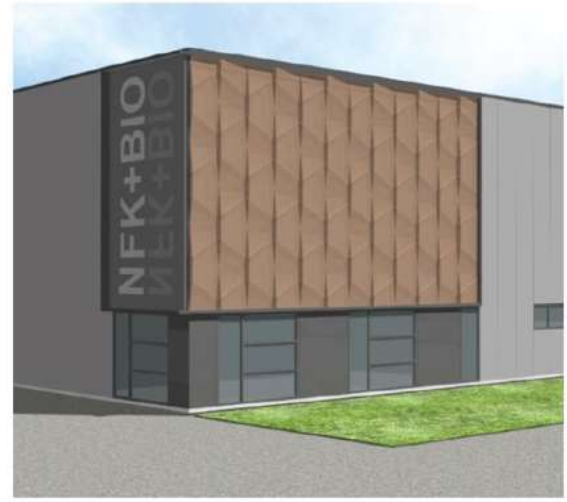

Fig. 5. Design of illuminated element (a) and reference object (Photo and Design by fried. A - Büro für Architektur) (b) 
With 15.840 LEDs the created screen resolution here is about $100 \times 50$ pixels. So the 25 extensively $3 \mathrm{D}$-formed elements in parametrical design are manufactured in one formwork with regard to resource efficiency and economical aspects. The biobased sandwich facade will be finished in spring 2018 as reference object of the determination.

\section{Results and Discussion}

\subsection{Properties of the NFRP face sheets and cardboard core}

The water vapour diffusion of the NFRP face sheet laminate was classified as resistant with a water vapour transmission rate of $36.1 \mathrm{mg} /\left(\mathrm{m}^{2} \times \mathrm{h}\right)$ after 24 days and corresponded to class V3 according to DIN EN 1063. Using a Cobb-Unger test apparatus, water absorption of 58 $\mathrm{g} / \mathrm{m}^{2}$ in $60 \mathrm{~s}$ were determined in the coated cardboard core (cardboard without coating: 63 $\mathrm{g} / \mathrm{m}^{2}$ ). But the resistant face sheet laminates, according to water vapour diffusion, showed that the sandwich composite works like a closed system, where moisture almost can't entry into the composite and into the cardboard structure. So the water absorption of the cardboard core has a reduced influence in the biobased sandwich composite. With a special clamp-in valve with semipermeable membrane even the surplus moisture inside of the sandwich element can diffuse outside. Regarding flammability and flame dispersion the coated cardboard core passed all requirements according to class E based on EN ISO 11925-2. When the cardboard core is effected by fire the remained water of the sodium silicate coating is released whilst foam formation. Because of that, the flammability and flame dispersion is handicapped. After flame exposure the cardboard core has a self-extinguished behaviour. The cardboard core had a determined shear strength of $0.1 \mathrm{MPa}$ and a shear modulus of $7 \mathrm{MPa}$, which is comparable with traditional PUR-foam sandwich elements (shear strength about 0.2 $\mathrm{MPa}$, shear modulus about $5 \mathrm{MPa}$ ).

\subsection{Properties of the biobased sandwich}

The biobased sandwich element has a sound reduction index of $42 \mathrm{~dB}$, determined by transfer-matrix method by SONG und BOLTON [14] and according to DIN EN ISO 717-1 (Figure 6, a). The significant decrease of the sound reduction index at $500 \mathrm{~Hz}$ (Figure 6, a) can be ascribed with coincidence frequency, where the wavelength of the airborne sound correlates with the flexible shaft of the composite. In comparison to traditional sandwich elements for facades (consisting of aluminium face sheets and PUR foam core) with a sound reduction index of about $26 \mathrm{~dB}$, the biobased sandwich composite outdo the requirements for acoustical behaviour. Using the institutes own test cabinet, the coefficient of thermal conductivity of $0.18 \mathrm{~W} /(\mathrm{m} \times \mathrm{K})$ was determined for the biobased sandwich composite. This comparatively high coefficient of thermal conductivity results from air circulation inside the core compartments. For a reduced thermal conductivity the construction of the cardboard core element could be adjusted with special consideration of system weight or an additional layer of heat insulation could be integrated into the sandwich system. Furthermore the biobased sandwich composite is classified as flame retardant and corresponded to class of fire behaviour B - s3, d0 according to DIN EN 13501-1, with unlimited smoke production and no flaming droplets. In general this complies the condition for fire behaviour of facade elements on buildings. 


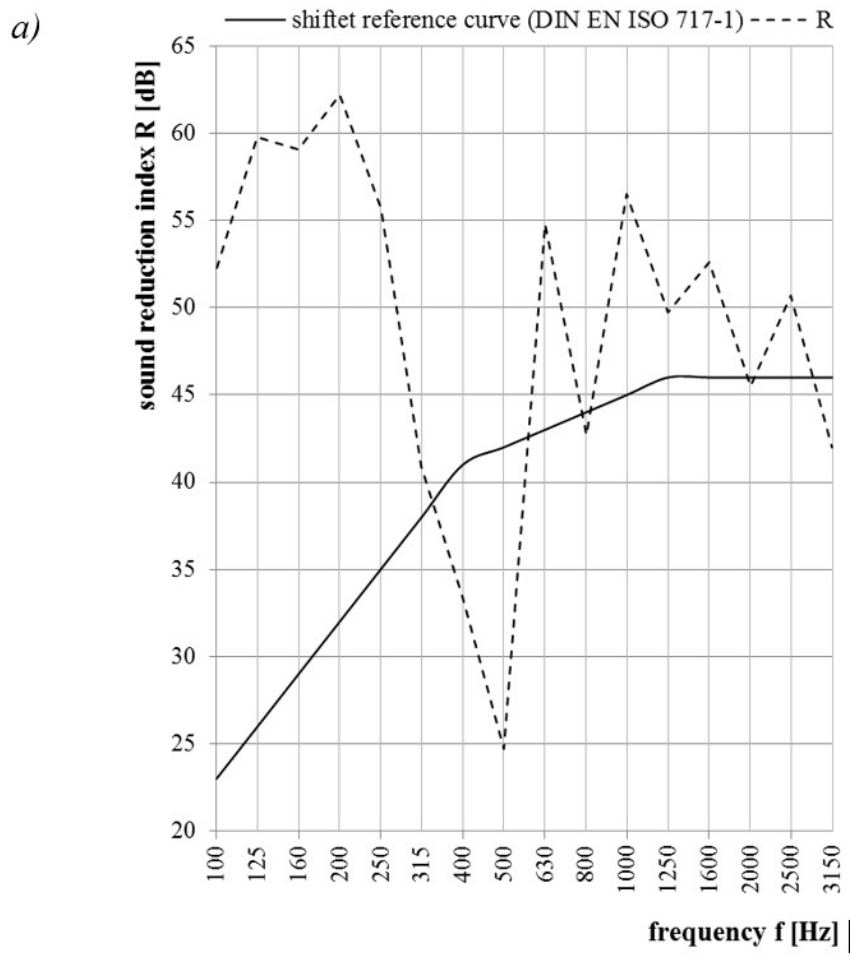

Fig. 6. Sound reduction index $(\mathrm{R})$ of biobased sandwich element in dependence of the frequency

\section{Conclusions}

At the current stage of the development, a biobased sandwich façade element was able to be implemented using renewable resources in lightweight construction method. Arising from the specifications placed on the biobased sandwich element, the followings were developed in the context of the presented research: load-bearing NFRP face sheets were assembled, a cardboard core structure with special coating was developed and integrated into the sandwich composite, a formwork system at prototype scale was designed enabling the biobased sandwich elements to be produced with an efficiency- and application-oriented approach and examined in practically investigations. Integrating flax fibres in a biobased epoxy resin generated load-bearing face sheets with a positive effect on water vapour diffusion regarding the core component. Proof was furnished in mechanical investigations that the core element of the sandwich facade can be made of coated cardboard structure. Proof was also given of fire retardant, resistance of flame dispersion and flaming droplets, as well as good sound reduction. But, especially in regard to high thermal conductivity further investigations will be realized to comply requirements under practice conditions regarding to EnEV 2016. Furthermore, the integration of illumination was achieved, which builds the unique characteristic of the sandwich facades.

This new biobased sandwich facade meets requirements as regards resource efficiency in combination with modern architecture. Especially the use of cardboard and natural fibres for facade elements can be exemplary for following projects to increase the use of renewable raw materials. 
We are very grateful to our donor of subsidies "FNR-Fachagentur Nachwachsende Rohstoffe e.V.", BMEL and our associate partners Fiber-Tech Group and richter \& hess Verpackungsservice GmbH.

\section{References}

1. K. Tichelmann, „Schwerpunkt Nachhaltigkeit - Eigenschaften und Potentiale des Leichtbaus“, Bau.Genial (2007)

2. W. Haase et al, Ernst \& Sohn Verl. Arch. tech. Wiss. GmbH \& Co. KG, Bautechnik 88, 2, 69-75 (2011)

3. G. W. Ehrenstein „Faserverbundkunststoffe. Werkstoffe - Verarbeitung Eigenschaften“"(2006)

4. J. Mühsig et al. „Karosserie aus Naturfasern und Pflanzenöl“, Kunstst., 3. (2007)

5. O. Türk, Spring. Fachm., DOI 10.1007/978-3-8348-2199-7 (2014)

6. N. Paul. „Spatenstich für ein Bürogebäude der neuen Generation“; Fachag. Nachwachs. Rohst. e.V. (2010)

7. J. Holbery, D. Houston, JOM, November (2006)

8. J. Howarth et, In J Cl. Prod., 81, 46-50 (2014).

9. C. Köhler, "Biobased plastics for exterior facades", Biopl. Mag., 8, 12-14 (2013)

10. M. Vermeulen, "World's first biobased façade", (2013).

11. J. Li, J. Knippers, Intern. J. Sp. Str., 30, 2. (2015)

12. E. Rudolph et al, Proc. Eight Intern. Conf. Fibre-Reinf. Polymer Comp. in Civil Eng. (J.G. Teng, J.G. Dai 2016)

13. S. Gelbrich, „Funktionsintegrative Leichtbaustrukturen für Tragwerke im Bauwesen“, Universitätsverlag Chemnitz (2016).

14. B. Song, J. Bolton, J. acous. Soc. Am., 107, 3 (2000) 